Supporting Information

\title{
Dual-functional Ti(IV)-IMAC material enables simultaneous enrichment and separation of diverse glycopeptides and phosphopeptides
}

\author{
Junfeng Huang, ${ }^{1}$ Xiaoyan Liu, ${ }^{2}$ Danqing Wang, ${ }^{4}$ Yusi Cui, ${ }^{4}$ Xudong Shi, ${ }^{3}$ Jing Dong, ${ }^{2}$ \\ Mingliang Ye, 2,* Lingjun $\mathrm{Li}^{1,4, *}$
}

${ }^{1}$ School of Pharmacy, University of Wisconsin-Madison, Madison, WI 53705, USA. Email:

lingjun.1i@wisc.edu

${ }^{2}$ Key Laboratory of Separation Sciences for Analytical Chemistry, National Chromatographic

R\&A Center, Dalian Institute of Chemical Physics, Chinese Academy of Sciences (CAS),

Dalian, China. Email: mingliang@dicp.ac.cn

${ }^{3}$ Department of Surgery, University of Wisconsin-Madison, Madison, WI 53705, USA.

${ }^{4}$ Department of Chemistry, University of Wisconsin-Madison, Madison, WI 53705, USA.

${ }^{*}$ Corresponding author. M.Y. (email: mingliang@dicp.ac.cn) or L.L. (email:

lingjun.1i@wisc.edu). 
Table of Contents

\section{Experimental section}

\section{Data availability.}

Figure S1. Distributions of sialic acid numbers of sialylated glycopeptides in each fraction.

Figure S2. Glycopeptide fractionation with conventional HILIC approach. (A) Total Nglycopeptide and sialylated glycopeptide identification results. (B) Sialylated glycopeptide ratio. (C) M6P glycopeptide identification results.

Figure S3. Comparison of mouse lung glycoproteome profiled in this study and the published data.

Table S1. MALDI-TOF MS analysis of HILIC-mode Ti-IMAC enriched peptides from $\beta$-casein and RNase B digest mixture with or without fractionation.

Table S2. Comparison of mouse lung ACE glycoforms profiled in this study and previously published data.

\section{References}




\section{Experimental section}

Sample preparation. Weigh $1 \mathrm{mg}$ of standard phosphoprotein $\beta$-casein and standard glycoprotein Ribonuclease B (RNase B) and dissolve them in $125 \mathrm{ml} \mathrm{8M}$ urea and $50 \mathrm{mM}$ TEAM buffer (pH 8.0), respectively. The mouse lung tissue was collected from male adult C57BL/6 mice. The tissue sample was sliced into 1-2 cubic millimeter pieces in clean dish with ice bath and washed with $150 \mathrm{mM}$ ice cold PBS buffer for 3 times. Then they were homogenized and lysed in a homogenization buffer consisting of 4\% v/v SDS, $65 \mathrm{mM}$ DTT, $150 \mathrm{mM} \mathrm{NaCl}$, and $25 \mathrm{mM}$ Tris (pH 7.4) (1 protease inhibitor tablet (Roche, Mannheim, Germany) and 1 phosphatase inhibitor tablet (Roche, Mannheim, Germany) were added in every $10 \mathrm{~mL}$ of the lysis buffer). Lysed buffer was continually sonicated in a probe sonicator with $60 \mathrm{~W}$ energy and pulse $5 \mathrm{~s}$ on $5 \mathrm{~s}$ off for 60 cycles. The homogenates were centrifuged with 3000 x g for $15 \mathrm{~min}$ and the supernatants were collected and poured into 5-fold ice cold precipitation buffer (acetone: ethanol: acetic acid=50: 50: 0.1). The precipitation was put in $-20{ }^{\circ} \mathrm{C}$ for $12 \mathrm{~h}$ and then was centrifuged with $3000 \mathrm{x} \mathrm{g}$ at $4{ }^{\circ} \mathrm{C}$ for $15 \mathrm{~min}$. The protein pellet was washed with $10 \mathrm{ml}$ ice cold precipitation buffer twice and centrifuged with $3000 \mathrm{x}$ g for $15 \mathrm{~min}$ to remove the supernatants. The pellet was put in hood for $15 \mathrm{~min}$ to dry the remaining precipitation buffer and then was re-dissolved in $8 \mathrm{M}$ urea and $50 \mathrm{mM}$ TEAB buffer ( $\mathrm{pH}$ 8.0). Protein concentration was measured by a BCA assay kit (Thermo Fisher Scientific, San Jose, CA) and stored in $-80{ }^{\circ} \mathrm{C}$.

Protein digestion. Take out $1 \mathrm{mg}$ of standard phosphoprotein, glycoprotein, and mouse lung protein samples, respectively. The samples were treated with $10 \mathrm{mM}$ dithiothreitol (DTT) for $1 \mathrm{~h}$ to reduce the disulfide bonds. After reduction, the samples were alkylated with $20 \mathrm{mM}$ iodoacetamide for $30 \mathrm{~min}$ in the dark to block the reduced cysteine. The samples were quenched 
by adding $10 \mathrm{mM}$ DTT for $5 \mathrm{~min}$. In the end, the sample buffer was diluted to $1 \mathrm{M}$ urea with 50 mM TEAB and trypsin (Promega, Madison, WI) was added to the samples with protein: trypsin ratio at 50:1 and incubated at $37{ }^{\circ} \mathrm{C}$ water bath for $16 \mathrm{~h}$. Digested samples were stored at $-80{ }^{\circ} \mathrm{C}$ for later use.

Typical Ti(IV)-IMAC enrichment and elution. Ti(IV)-IMAC adsorbents were home-made and the enrichment protocol was adapted from our previous protocol. ${ }^{1-3}$ Briefly, the $200 \mu \mathrm{g}$ tryptic mouse lung peptide mixture was added in the loading buffer $(80 \%$ acetonitrile $(\mathrm{ACN})(\mathrm{v} / \mathrm{v})$ and $6 \%$ trifluoroacetic acid (TFA) (v/v)) with 1:1 ratio (v/v) and then they were incubated with Ti(IV)IMAC adsorbents with a ratio of 1:10 (w/w) for $30 \mathrm{~min}$. Then the non-specific adsorbed peptides on the surface of adsorbents were washed sequentially by washing buffer $1(50 \% \mathrm{ACN}(\mathrm{v} / \mathrm{v}) 6 \%$ TFA (v/v) and $200 \mathrm{mM} \mathrm{NaCl})$ and washing buffer $2(30 \% \mathrm{ACN}(\mathrm{v} / \mathrm{v})$ and $0.1 \% \mathrm{TFA}(\mathrm{v} / \mathrm{v}))$. Finally, the enriched phosphopeptides and M6P glycopeptides were eluted from the adsorbents with $10 \%$ $\mathrm{NH}_{4} \mathrm{OH}(\mathrm{v} / \mathrm{v})$. After centrifugation at $20,000 \mathrm{x} \mathrm{g}$ for $5 \mathrm{~min}$, the supernatant was collected and immediately dried down in SpeedVac. Samples were stored at $-20^{\circ} \mathrm{C}$ and re-dissolved in $1 \%$ formic acid (FA) before LC-MS/MS analysis and load 15\% of each sample for analysis.

Typical HILIC enrichment and elution. HILIC enrichment was performed with homemade HILIC stage-tip which uses a neutral, polar material (PolyHYDROXYETHYL A: $12 \mu \mathrm{m}$ and 300 $\AA$ from PolyLC Inc.). Briefly, $2 \mathrm{mg}$ of cotton wool was weighed and inserted into a $200 \mu \mathrm{L}$ pipette tip. Place the pipette tip on a $2 \mathrm{~mL}$ sample vial with the help of an adapter unit. HILIC beads were dissolved into $1 \%$ trifluoroacetic acid (TFA) solvent and the HILIC beads slurry was vortexed for 15 min to activate the HILIC beads. Transfer the HILIC slurry onto the top of the cotton wool. Centrifuge the sample vial to remove the solvent at $500 \mathrm{xg}$ for $2 \mathrm{~min}$. Add $200 \mu \mathrm{L} 1 \% \mathrm{TFA}$ to flush the beads. Centrifuge the sample vial at $500 \mathrm{xg}$ for $2 \mathrm{~min}$ to remove the liquid. Condition the 
HILIC beads with $200 \mu \mathrm{L} 80 \%$ ACN/1\% TFA for three times. $200 \mu \mathrm{g}$ tryptic mouse lung sample was dissolved in $80 \%$ ACN $/ 1 \%$ TFA and loaded onto the HILIC stage-tip. Centrifuge the sample vial at $500 \mathrm{xg}$ for $2 \mathrm{~min}$ and flow through of the sample was re-loaded to the HILIC stage-tip twice. Then wash away the non-glycopeptides with $200 \mu \mathrm{L} 80 \%$ ACN/ 1\% TFA for three times, and then elute the glycopeptides with $300 \mu \mathrm{L} 0.1 \%$ FA water. The sample was immediately dried down in SpeedVac. Samples were stored at $-20^{\circ} \mathrm{C}$ and re-dissolved in $0.1 \%$ formic acid (FA) before LCMS/MS analysis and load 15\% of each sample for analysis.

Fractionation method: Two aliquots of $250 \mu \mathrm{g}$ tryptic digested mouse lung sample were dissolved in $80 \% \mathrm{ACN} / 1 \% \mathrm{TFA}$ and loaded onto the HILIC stage-tip. Centrifuge the sample vial at $500 \mathrm{xg}$ for $2 \mathrm{~min}$ and the flow-through sample was re-loaded to the HILIC stage-tip twice. The nonglycopeptides were washed with $200 \mu \mathrm{L} 80 \% \mathrm{ACN} / 1 \%$ TFA for three times, followed by elution of the glycopeptides with $60 \% \mathrm{ACN}(\mathrm{v} / \mathrm{v})$ and $0.1 \% \mathrm{FA}(\mathrm{v} / \mathrm{v}), 40 \% \mathrm{ACN}(\mathrm{v} / \mathrm{v})$ and $0.1 \% \mathrm{FA}(\mathrm{v} / \mathrm{v})$, $20 \% \mathrm{ACN}(\mathrm{v} / \mathrm{v})$ and $0.1 \% \mathrm{FA}(\mathrm{v} / \mathrm{v}), 0.1 \% \mathrm{FA}(\mathrm{v} / \mathrm{v})$, respectively. The elutions from the two aliquots of samples were combined and were immediately dried down in SpeedVac. Samples were stored at $-20{ }^{\circ} \mathrm{C}$ and re-dissolved in $0.1 \%$ formic acid (FA) before LC-MS/MS analysis and $20 \%$ of each sample was loaded for analysis.

\section{MALDI-TOF and NanoLC-MS/MS analysis.}

Standard samples were tested on a Bruker Rapiflex MALDI-TOF/TOF instrument (Bruker Daltonik, Bremen, Germany) in positive ion mode with 2,5-Dihydroxybenzoic acid matrix (Sigma Aldrich, St. Louis, USA). Ion source parameters: laser energy $70 \%$, frequency $200 \mathrm{~Hz}$, laser $355 \mathrm{~nm}$ and each data collection of 10,000 shots.

Complex samples were analyzed with an Ultimate 3000 nanoLC coupled to an Orbitrap Fusion Lumos Tribrid mass spectrometer (Thermo Fisher Scientific, San Jose, CA). Re-dissolved sample 
was injected onto a $75 \mu \mathrm{m}$ i.d. $\times 15 \mathrm{~cm}$ length homemade column with an integrated $\mathrm{HF}$ etched emitter tip and packed with $1.7 \mu \mathrm{m}, 130 \AA$, BEH $\mathrm{C}_{18}$ material from a Waters UPLC column (Waters, Milford, MA). Peptides were separated with a gradient that ramped from $97 \%$ solvent A $(0.1 \%$ FA in $\left.\mathrm{H}_{2} \mathrm{O}\right)$ and $3 \%$ solvent $\mathrm{B}(0.1 \% \mathrm{FA}$ in $\mathrm{ACN})$ to $30 \%$ solvent $\mathrm{B}$ over 80 min and then kept each of $75 \%$ solvent $\mathrm{B}, 95 \%$ solvent $\mathrm{B}$, and $100 \%$ solvent $\mathrm{A}$ for $10 \mathrm{~min}$. The flow rate was set at 300 $\mathrm{nL} / \mathrm{min}$. MS method was set according to the following parameters: MS scan range $(\mathrm{m} / \mathrm{z})=400$ 2000 in positive ion mode; resolution $=120,000 ;$ AGC target $=1.0 \mathrm{e}^{6}$; maximum injection time $=250 \mathrm{~ms}$; included charge state $=2-6$; dynamic exclusion duration $=30 \mathrm{~s} . \mathrm{MS} / \mathrm{MS}$ method is a top 20 data-dependent acquisition (DDA) mode in which all MS/MS dissociations were performed with higher energy collisional dissociation $(\mathrm{HCD})$ : resolution $=60,000$; $\mathrm{AGC}$ target $=2.0 \mathrm{e}^{5} ;$ maximum injection time $=150 \mathrm{~ms}$; collision energy $=30 \%$. 


\section{Data availability}

The RAW MS data of mouse lung samples enriched with different methods, as well as the original search results of Byonic have been uploaded to the PRIDE partner repository with access code: Project accession: PXD020196 (Reviewer account details: Username: reviewer41137@ebi.ac.uk, Password: C5wlWyBG) 


\section{Sialic acid distribution}

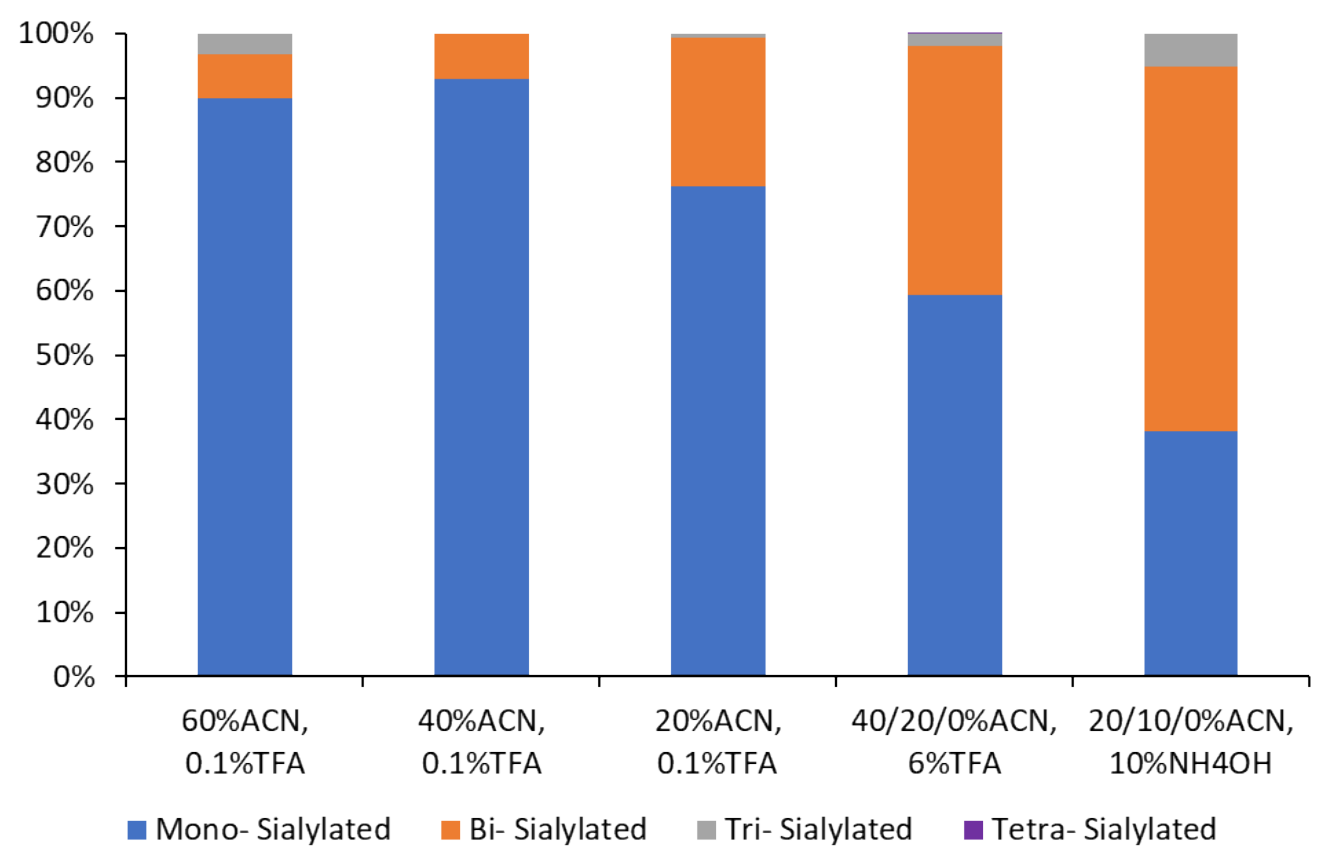

Figure S1. Distributions of sialic acid numbers of sialylated glycopeptides in each fraction. 


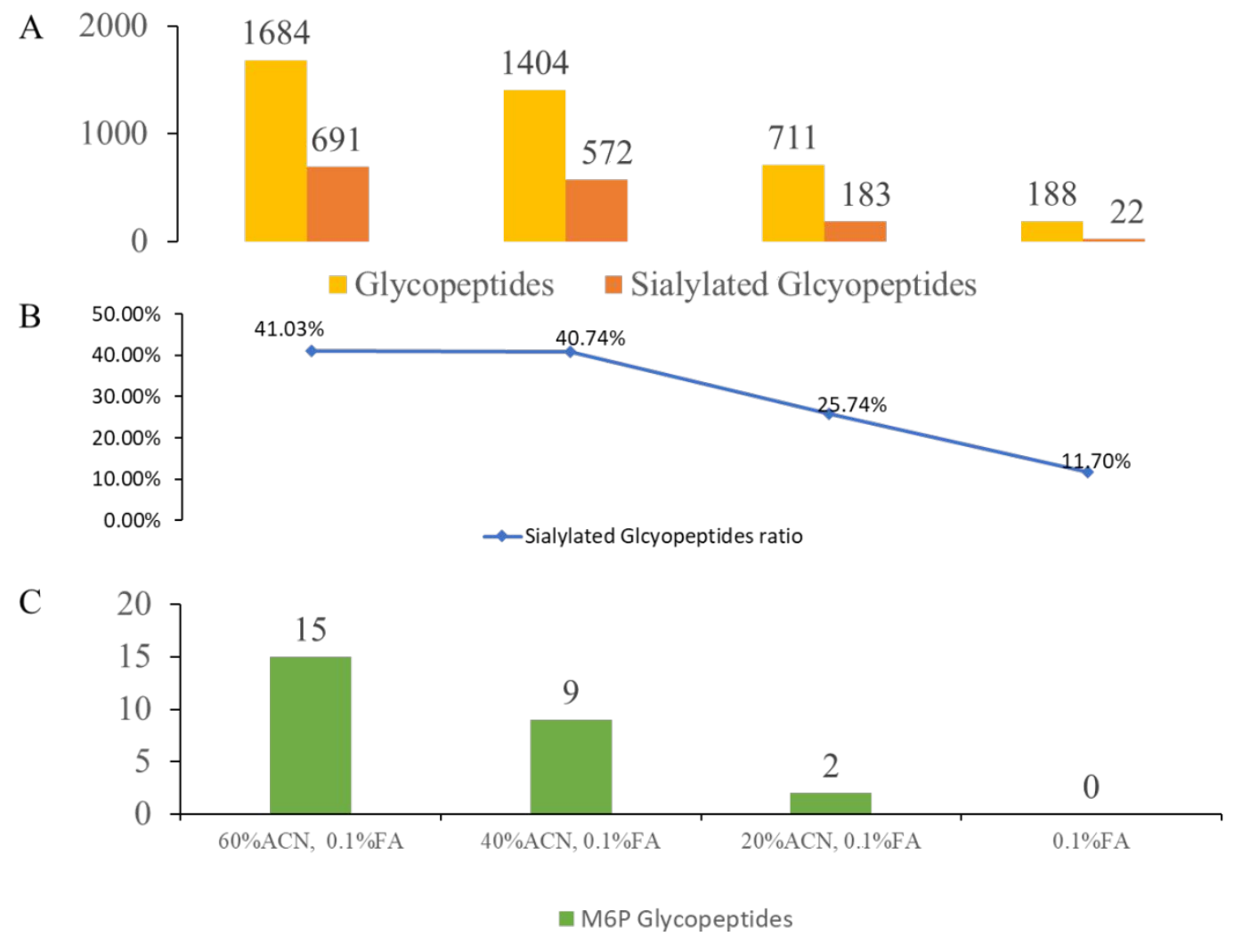

Figure S2. Glycopeptide fractionation with conventional HILIC approach. (A) Total Nglycopeptide and sialylated glycopeptide identification results. (B) Sialylated glycopeptide ratio. (C) M6P glycopeptide identification results. 
A

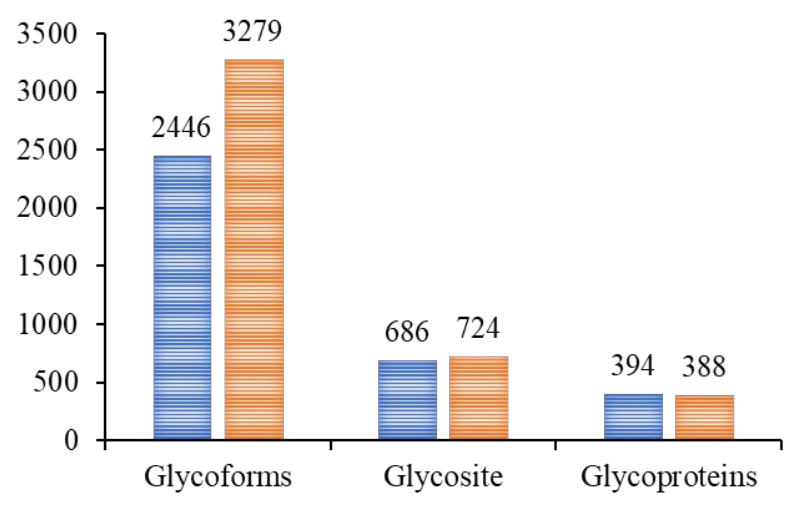

C

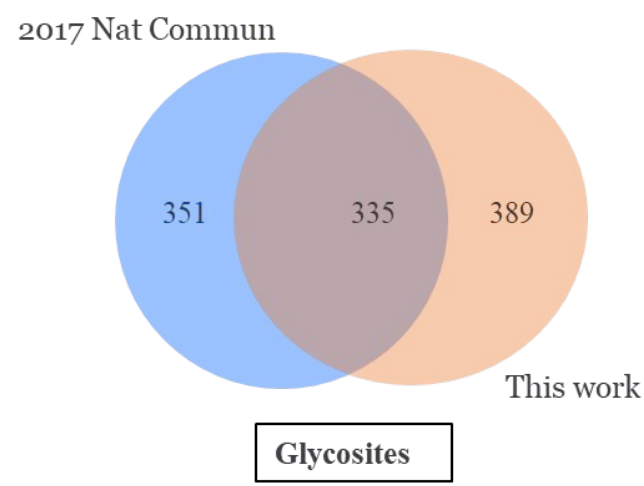

B

2017 Nat Commun

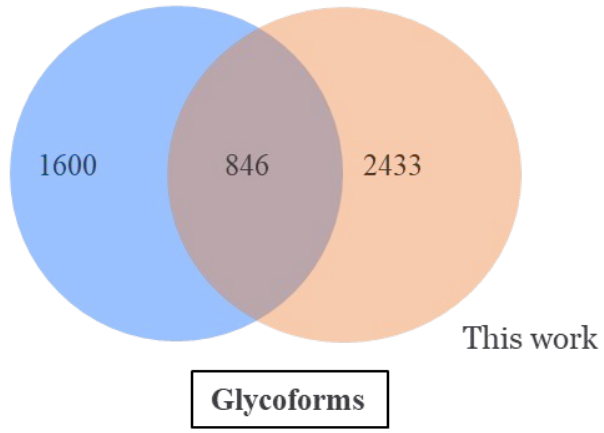

$\mathrm{D}$

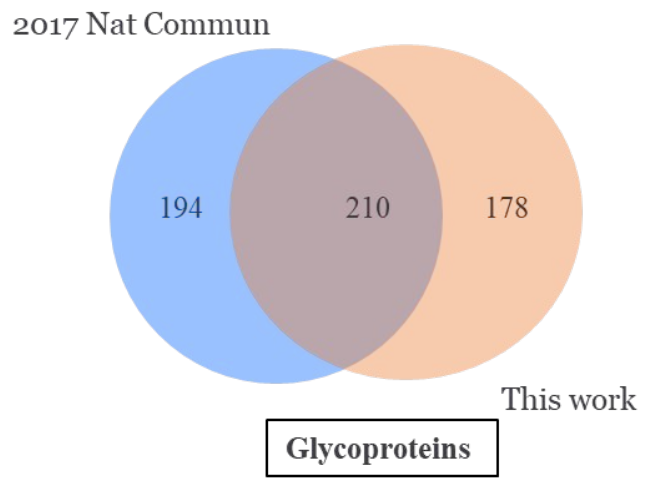

Figure S3. Comparison of mouse lung glycoproteomes profiled in this study and previously published data. 
Table S1. MALDI-TOF MS analysis of HILIC-mode Ti-IMAC enriched peptides from $\beta$-casein and RNase B digest mixture with or without fractionation.

\begin{tabular}{|c|c|c|c|c|c|c|}
\hline Protein & Peptide & Glycosite & Glycan & {$[\mathbf{M}+\mathbf{H}]^{+}$} & $\begin{array}{l}\text { No } \\
\text { fractionation }\end{array}$ & Fractionation \\
\hline Rnase B & NLTK & Asn-60 & $\begin{array}{l}\text { GlcNAc2 } \\
\text { Man5 }\end{array}$ & 1691.71 & 1 & 1 \\
\hline Rnase B & NLTK & Asn-60 & $\begin{array}{l}\text { GlcNAc2 } \\
\text { Man6 }\end{array}$ & 1853.76 & 1 & 1 \\
\hline Rnase B & SRNLTK & Asn-60 & $\begin{array}{l}\text { GlcNAc2 } \\
\text { Man5 }\end{array}$ & $\begin{array}{ll}1934.84 \\
\end{array}$ & & 1 \\
\hline Rnase B & NLTKDR & Asn-60 & $\begin{array}{l}\text { GleNAc2 } \\
\text { Man5 }\end{array}$ & 1962.84 & & 1 \\
\hline Rnase B & NLTK(cam)DR & Asn-60 & $\begin{array}{l}\text { GlcNAc2 } \\
\text { Man5 }\end{array}$ & 2005.84 & & 1 \\
\hline Rnase B & NLTK & Asn-60 & $\begin{array}{l}\text { GlcNAc2 } \\
\text { Man7 }\end{array}$ & 2015.82 & & 1 \\
\hline Rnase B & SRNLTK & Asn-60 & $\begin{array}{l}\text { GlcNAc2 } \\
\text { Man6 }\end{array}$ & 2096.90 & & 1 \\
\hline Rnase B & NLTKDR & Asn-60 & $\begin{array}{l}\text { GleNAc2 } \\
\text { Man6 }\end{array}$ & 2124.89 & & 1 \\
\hline Rnase B & NLTK(cam)DR & Asn-60 & $\begin{array}{l}\text { GlcNAc2 } \\
\text { Man6 }\end{array}$ & 2167.90 & & 1 \\
\hline Rnase B & NLTK & Asn-60 & $\begin{array}{l}\text { GlcNAc2 } \\
\text { Man8 }\end{array}$ & 2177.87 & & 1 \\
\hline Rnase B & SRNLTK & Asn-60 & $\begin{array}{l}\text { GIcNAc2 } \\
\text { Man7 }\end{array}$ & 2258.95 & & 1 \\
\hline Rnase B & NLTKDR & Asn-60 & $\begin{array}{l}\text { GlcNAc2 } \\
\text { Man7 }\end{array}$ & 2286.94 & 1 & 1 \\
\hline Rnase B & NLTK & Asn-60 & $\begin{array}{l}\text { GleNAc2 } \\
\text { Man9 }\end{array}$ & 2339.92 & & 1 \\
\hline Rnase B & SRNLTK & Asn-60 & $\begin{array}{l}\text { GleNAc2 } \\
\text { Man8 }\end{array}$ & 2421.00 & & 1 \\
\hline
\end{tabular}




\begin{tabular}{|l|l|l|l|l|l|l|}
\hline Rnase B & NLTKDR & Asn-60 & GlcNAc2 & 2449.00 & 1 & Man8 \\
\hline Rnase B & SRNLTK & Asn-60 & GlcNAc2 & 2583.05 & & 1 \\
\hline$\beta$-casein & FQ[pS]EEQQQTEDELQDK & & Man9 & & 1 \\
\hline$\beta$-casein & ELEELNVPGEIVE[pS]L[pS][pS][pS]EESITR & & & 2061.83 & 1 & 1 \\
\hline$\beta$-casein & RELEELNVPGEIVE[pS]L[pS][pS][pS]EESITR & & & 3122.27 & 1 & 1 \\
\hline
\end{tabular}


Table S2. Comparison of mouse lung ACE glycoforms profiled in this study and previously published data.

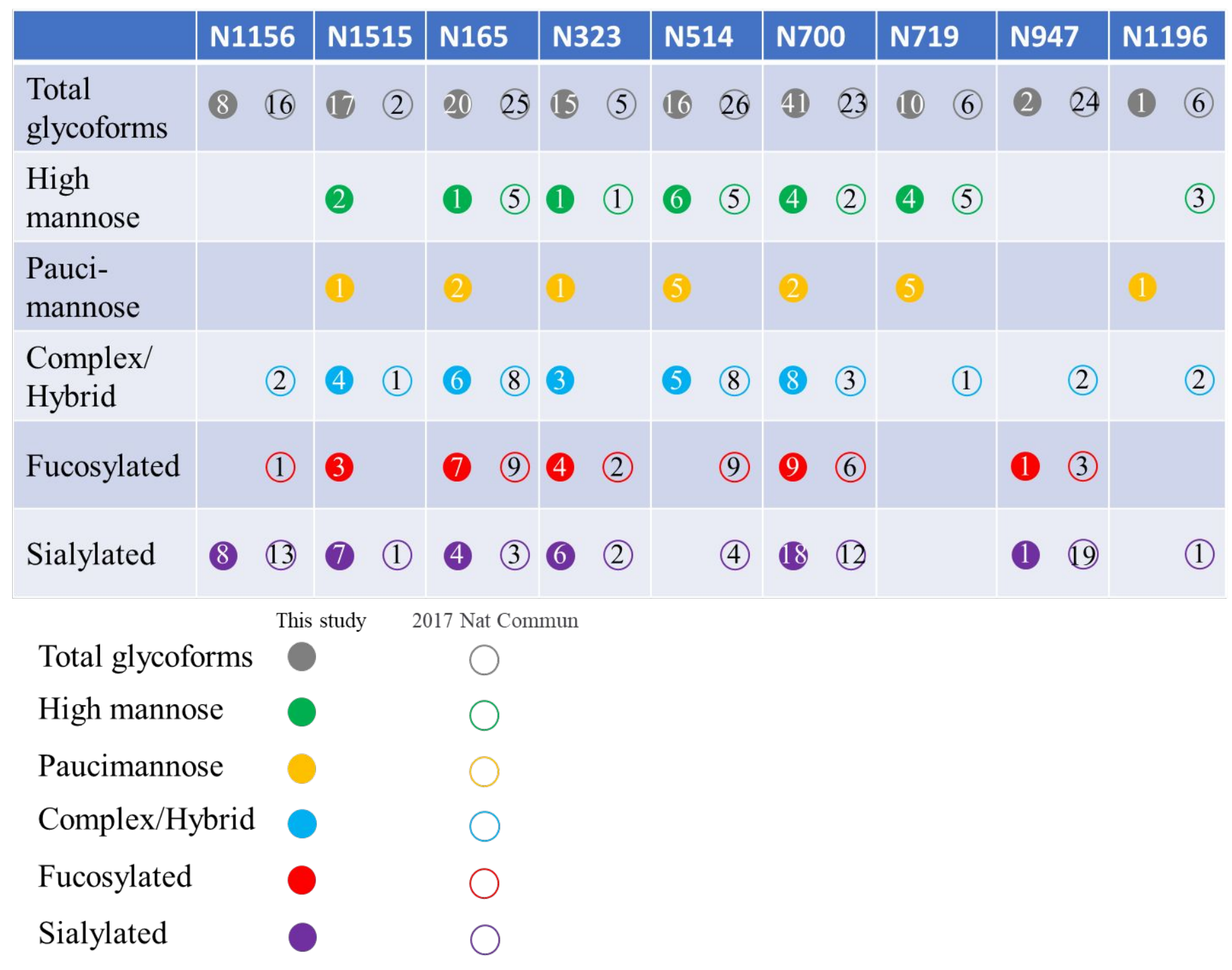




\section{References}

(1) Zhou, H.; Ye, M.; Dong, J.; Corradini, E.; Cristobal, A.; Heck, A. J. R.; Zou, H.; Mohammed, S. Robust phosphoproteome enrichment using monodisperse microsphere-based immobilized titanium (IV) ion affinity chromatography. Nat. Protoc. 2013, 8, 461-480.

(2) Huang, J.; Qin, H.; Dong, J.; Song, C.; Bian, Y.; Dong, M.; Cheng, K.; Wang, F.; Sun, D.; Wang, L.; Ye, M.; Zou, H. In Situ Sample Processing Approach (iSPA) for Comprehensive Quantitative Phosphoproteome Analysis. J. Proteome Res. 2014, 13, 3896-3904.

(3) Liu, Z.; Wang, F.; Chen, J.; Zhou, Y.; Zou, H. Modulating the selectivity of affinity absorbents to multi-phosphopeptides by a competitive substitution strategy. $J$. Chromatogr. A 2016, 1461, 35-41. 